\title{
Investigating climate change vulnerability and planning for adaptation: Learning from a study of climate change impacts on the Mountain Gorilla in the Albertine Rift
}

\author{
Daniel John McGahey*, David Gerard Williams, Philip Muruthi, David lan Loubser
}

African Wildlife Foundation, AWF Conservation Centre, Nairobi, Kenya;

*Corresponding Author: dmcgahey@awf.org

Received 28 March 2013; revised 28 April 2013; accepted 13 May 2013

Copyright (c) 2013 Daniel John McGahey et al. This is an open access article distributed under the Creative Commons Attribution License, which permits unrestricted use, distribution, and reproduction in any medium, provided the original work is properly cited.

\begin{abstract}
Climate change represents an unprecedented challenge for the conservation and management of endangered species and habitats. Effective climate smart conservation will require robust predictions of vulnerability and future changes, along with the design and prioritisation of effective adaptation planning and management responses that are clearly linked to projected climate impacts. To achieve this goal, conservation managers urgently need practical tools and approaches for vulnerability assessment and adaptation planning. This article explores lessons emerging from a recent vulnerability assessment and adaptation planning exercise conducted on the impact of climate change for mountain gorilla (Gorilla beringei beringei). We describe the main findings emerging from this initiative and explore key lessons for climate change vulnerability assessment and adaptation planning for conservation management. Data limitations were a key factor determining the utility of model outputs and we stress the importance of stakeholder engagement and collaboration throughout the vulnerability assessment and adaptation planning cycle. These findings are of relevance to conservation practitioners seeking to incurporate climate change considerations into ongoing management planning for endangered species conservation.
\end{abstract}

Keywords: Conservation Planning; Endangered Species; Mountain Gorilla; Climate Change

Adaptation; Vulnerability Assessment

\section{INTRODUCTION}

Although land use change remains the main driver of species extinction and habitat loss, climate change is predicted to become equally or more important in the coming decades [1]. Climate impacts are already being observed in widespread shifts in species ranges, phenological responses, disruption of ecosystem services and the termination of evolutionary potential. To minimize deleterious consequences for biodiversity it will therefore be essential that conservation planning becomes climate sensitive.

In spite of the proliferation of non-equilibrium concepts in ecology, the prevailing practice of conservation remains planning for a relatively stable environment [2]. The creation, securing and management of protected areas, wildlife corridors and buffer zones remain key approaches to habitat and species conservation. Yet these approaches evolved under climatic conditions unlikely to be experienced again, and resource managers can no longer look to past climatic trends to guide conservation planning [3]. Instead, conservation planning should be able to anticipate an increasingly different and uncertain future climate [4].

The theory and practice of climate change vulnerability assessment and adaptation planning in conservation has advanced significantly over the past decade [cf. 3-6]. That said, there is still a shortage of universally accepted tools and approaches to guide new adaptation initiatives in conservation [7]. Moreover, practical examples from tropical regions are scarce [8].

This article explores lessons emerging from a climate change vulnerability assessment and adaptation planning exercise conducted on the mountain gorilla (Gorilla beringei beringei) and its afromontane habitat in 2010 [9]. Given the scarcity of practical examples and applied 
tools for climate change vulnerability assessment and adaptation planning for tropical conservation management, there may be important lessons to be learnt from this project.

The project was implemented by the African Wildlife Foundation (AWF) and the International Gorilla Conservation Programme (IGCP) in partnership with EcoAdapt. The project aimed to build an understanding of climate impacts upon the mountain gorilla and its habitat, in order to identify key elements of an adaptation framework for the species, including priority adaptation strategies and actions.

The article begins by providing an overview of the approach used by the project team, followed by a summary of the key findings and implications for species and habitat management. Next, the key lessons learnt from this process are discussed, focusing on lessons for the vulnerability assessment process and subsequent adaptation planning steps. Finally, we conclude by exploring the key implications for conservation practitioners seeking to incorporate climate change considerations into ongoing management planning.

\section{METHODS: DRAWING ON AVAILABLE TOOLS}

\section{The Framework Used}

The project aimed to build an understanding of the vulnerability of mountain gorilla and its habitat to climate change, and assess the scope for reducing this vulnerability through the integration of effective adaptation planning and tools into the current management framework. Five general steps were used to guide the design of a framework to understand vulnerability and develop an adaptation plan for the mountain gorilla [after 3,5,10,11]. These were 1) identification of goals for assessment; 2) assessment of vulnerability to climate change; 3) identification and design of management, planning or regulatory actions to address vulnerability; 4) design and enacting of monitoring; and 5), creation of an iterative process. Using these broad steps as an organising framework, the project aimed to work through steps 1 to 3 .

Primary scientific research was commissioned to develop species distribution models (SDMs) that created assessments of ecosystem and species distribution under various climate-envelope scenarios (step 2). The project also utilized the results of an initial climatological modeling assessment of climate impacts along the Albertine Rift carried out by the Wildlife Conservation Society (WCS) [cf. 12]. A further more complete discussion of the methodologies utilized in both of these works can be found in [9]. Expert opinion through a series of climate camp workshops [after 13] was then used to review, validate and assess the accuracy of model outputs, dis- cuss and agree on anomalies, and identify data gaps and priorities for future research or monitoring (steps $2 \& 4$ ). These workshops also began the process of developing an adaptation planning framework for the species (step 3), but further multi-stakeholder dialogue will be required with a more complete group including transboundary protected area authorities and relevant multisectoral authorities to develop this adaptation plan and mainstream it within current planning frameworks.

\section{RESULTS}

\subsection{Projected Climate and Ecological Changes}

The project benefited from the results of an initial assessment of climate impacts along the Albertine Rift by the Wildlife Conservation Society (WCS) [cf. 12]. This assessment used Intergovernmental Panel on Climate Change (IPCC) low resolution general circulation model multi-model global ensembles extracted for the Albertine Rift and downscaled to $50 \mathrm{~km}$ resolution. The modeling ran predictions under the SRES A2 greenhouse gas emissions scenario. Researchers from WCS also examined existing climate datasets from meteorological stations in the region for current trends over the last 50 years.

Examination of long-term temperature records from the Lwiro Research Station in the Democratic Republic of Congo indicated a warming trend of +2.1 oC over 53 years which exceeds that reported elsewhere in eastern Africa [14]. Modeling projected a region-wide thermal increase of 3.6 oC by 2090 relative to 1990 levels [14: p. 15]. It is thought that this could translate to a large upward displacement of species ranges and vegetation zones of approximately 600 to 700 metres relative to 1990 levels, but more detailed Species Distribution Models (SDM) are needed to confirm this.

Rainfall projections displayed marked changes in rainfall seasonality, as well as an overall rainfall increase in the longer term. However, models predicted a drying period centred around two decades either side of 2030 whereby mid-year decreases in rainfall are predicted, causing a longer dry season. When combined with the warming trends, this drying period might be indicative of an increasing threat of drought induced ecological change or increased threats from forest fires [14]. However, by 2090 rainfall levels are predicted to increase by 15 per cent relative to 1990 levels, with the largest increase predicted in the November-March period. This is expected to replace the existing short dry season with a relatively unimodal rainfall regime which could cause significant ecological impacts.

\subsection{Mountain Gorilla Vulnerability}

Mountain gorillas (Gorilla beringei beringei) are cate- 
gorized as Critically Endangered by the IUCN Red List [15]. There are approximately 880 mountain gorilla found in two isolated populations in Central East Africa. These are found in the Virunga Volcanoes region of Rwanda, Uganda and the Democratic Republic of Congo (DRC), and in the Bwindi Impenetrable National Park of Uganda.

Population modeling suggests the Virunga gorilla population is viable for at least the next 100 years in the absence of external disturbance, but could easily suffer severe decline from environmental perturbations such as habitat degradation [16-18]. Determining the sensitivity of mountain gorilla and its key herbaceous food species to climate change is complicated by various factors.

Mountain gorilla are primarily herbivores, feeding on the leaves, shoots, stems, bark, roots, flowers and fruits of various trees and herbaceous plants. In spite of being indistinguishable in terms of DNA [19], the Virunga and Bwindi populations occupy markedly different habitats and consequently have different dietary characteristics and thus potentially different sensitivities to climate change. The Bwindi population occupies a range of vegetation types across transitional and Afromontane forests, whereas the Virunga gorilla population occupies highaltitude montane forests with a dense herbaceous layer and low abundance of fruiting species [20,21]. Bwindi mountain gorillas occupy more than twice the home range of groups in the Virungas as a consequence of having far more tree species that produce seasonal fruits and therefore far greater proportion of fruit in their diets [22].

One of the keys to understanding the sensitivity and adaptive capacity of mountain gorilla to climate change will therefore be found in efforts to explore the feeding ecology and climate sensitivity of important food species. Climate changes that effect the phenology and abundance of key mountain gorilla food species may significantly affect ranging patterns and habitat use. In the Virungas, mountain gorilla depend mainly on perennially available herbs and vines, the abundance of which are mostly independent of rainfall [21]. Bamboo (Arundinaria alpina) is the only seasonally rainfall dependent species on which the Virunga mountain gorilla depend. Additional work should explore the likely impact of projected climate changes on the availability of bamboo in the Virungas and fruiting tree species in the Bwindi region.

The adaptive capacity of mountain gorillas themselves requires further investigation. While previous research on their feeding ecology demonstrates their dependence on a narrow range of plant species in each habitat, their ability to occupy a range of different habitats in the Virungas, appears to illustrate their dietary flexibility and possible high levels of adaptive plasticity [20]. That said, these adaptations occurred over evolutionary timescales and more work is required to establish whether individuals could adapt over an inter- or intra-generational timeframe.

Finally, the impact of climate change on the incidence and threat of forest fires across the mountain gorilla habitat could significantly increase their vulnerability. In 2009 a forest fire on Mount Muhabura of the Virungas burnt approximate 300 hectares. As predicted climate changes will likely lead to an initial reduction in rainfall, this drying of the forest will increase the threat of fire as a leading cause of habitat destruction [9].

\subsection{Species Distribution Modeling}

The species distribution modeling (SDM) utilized Maxent as a tool to model species response to a variety of projected climate scenarios [23]. The modeling used the WorldClim climate model dataset downscaled to 1 $\mathrm{km}$ grid resolution under the A2 and A1B emissions scenarios. Maxent employs a maximum entropy approach to predict species probability distributions using presenceonly species observations and environmental covariates as inputs, and performs well when compared to other similar SDM approaches [24].

Other input variables included topography using $1 \mathrm{~km}^{2}$ Shuttle Radar Topography Mission (SRTM) digital elevation models; monthly net primary productivity (NPP); mountain gorilla presence data from 44,780 observed points across the Virungas and Bwindi regions; and over 4941 recorded points of plants edible for mountain gorillas. The mountain gorilla presence and edible plant data represented best available datasets contributed from numerous long-term research and monitoring programmes. For more details on the methodology used see [25].

SDM performance was evaluated using additional census data to assess ability to predict present range and the best performing predictor variables were combined to produce the dataset determined most accurate for running the future scenarios. While the resulting models performed well under contemporary scenarios, model results diverged under future climate scenarios depending on model inputs. Models driven by temperature and elevation predicted the complete disappearance of gorilla habitat post 2050, for example.

Expert review of these outputs at the climate camp workshops generated heated debate but consensus that climate and elevation driven model outputs were most likely misleading, over-emphasizing mountain gorilla sensitivity to changes in temperature. Primatologists pointed to the fact that the mountain gorilla's closest relative, eastern lowland gorillas (Gorilla beringei graueri) occupy much lower elevations indicating that mountain gorilla are likely to be much more adaptable to changing temperatures. 
Temperature-driven model results were likely influenced by the fact that the current gorilla distribution data driving them derive from a population artificially restricted to higher elevations due to loss of habitat from land use change. Primatologists considered SDM outputs driven by Net Primary Productivity (NPP) to be more realistic. These model outputs even predicted that some lower elevation areas adjacent to parks will remain suitable under most future climate scenarios.

Overall, the workshop discussion revealed that while the modeling approach was sound, more data is needed in order to improve the value of model outputs under future climate scenarios. In particular, recognizing that the mountain gorilla's current range is limited by anthropogenic activity and not bioclimatic tolerance or habitat selection, future temperature-driven SDM efforts should include consideration of the historic gorilla range and diet, to represent the full climatic and habitat envelope of the species. Further research into the distribution and seasonal controls of important dietary plants could also be used to further develop SDMs based on NPP which might reveal more about mountain gorilla sensitivity to climate change, given their reliance upon a small range of plant food species.

\subsection{Stakeholder Validation \& Management Recommendations}

A large multi-stakeholder "climate camp" workshop drawing together scientists, non-governmental organisations, and protected area authorities from Rwanda, Uganda and the Democratic Republic of Congo was used to review, validate and assess the accuracy of modeling outputs. The workshop was also used to begin designing an adaptation framework for the mountain gorilla, including identifying priorities for management and programme interventions, along with monitoring and research.

The multi-stakeholder "climate camp" workshop attendees were divided into three working groups depending on specific technical background. There were: 1) park management; 2) gorilla ecology, health and conservation; and 3) socioeconomic. Table 1 shows the extended list of priority adaptation activities identified by each working group.

Priority adaptation activities were then ranked by the working groups, with a focus on identifying priority "no or low regret" actions that will "perform despite uncertainty". Under monitoring and research, investment in an integrated and coordinated network of meteorological stations was determined an immediate priority, given the inability of downscaled Global Circulation Model data to account for the complexity of climate dynamics around the Virunga Volcanoes region. The resulting data would be collated into a central database providing a resource for monitoring climate impacts at the micro-level. Simi- larly, the urgent need for additional data on the phenology and ecological dynamics of key mountain gorilla food species, particularly 20 important gorilla plants was stressed. The need for more research into the historical extent of mountain gorilla range using long-term ecology was also highlighted.

In terms of immediate priorities for conservation programming, the groups stressed the likely importance of indirect climate impacts upon people within reserveadjacent agricultural lands as a threat likely to surpass direct climate impacts on the mountain gorilla and its habitat. There is an urgent need to research these poverty-biodiversity-climate linkages in order to understand likely climate-driven societal impacts upon the mountain gorilla habitat. At the practical level, immediate investment building upon existing development programmes that enhance societal resilience to climate change such as investment in food and water security interventions was highlighted as a possible no-regret option.

Other no-regret conservation actions identified to be prioritized over the longer term included ecological investigation of viable wildlife corridors; integrating adaptive management principles into existing transboundary protected area planning; and the possibility of developing a fire early warning system. Extending work on disease and health issues was also stressed, given that introduction of a climate-propelled disease to the gorilla population from either an existing (e.g., malarial) or novel pathogen could prove catastrophic, considering the species' limited range

\section{LESSONS LEARNED}

\subsection{Stakeholder Collaboration}

The inclusion of a diverse range of expert stake-holders from scientists, non-governmental organisations and protected area planners proved vital in this project. Given the likely uncertainties inherent within SDM outputs, expert knowledge operating within a structured workshop framework proved essential in order to evaluate the utility and plausibility of varied model projections, and to identify data and research gaps in order to improve SDMs. Furthermore, close stakeholder collaboration is also required through the adaptation planning phase in order to design, identify and prioritize suitable adaptation and monitoring actions.

In the mountain gorilla case, stakeholder collaboration throughout the project cycle provided numerous benefits. Many stakeholder organizations in the region currently have limited experience with developing climate smart conservation actions or interpreting the necessary uncertainties in climate science needed to develop an adaptation plan. Including stakeholders in both the process of validating the vulnerability assessment and developing 
Table 1. Priority mountain gorilla adaptation strategies identified by expert stakeholder groups.

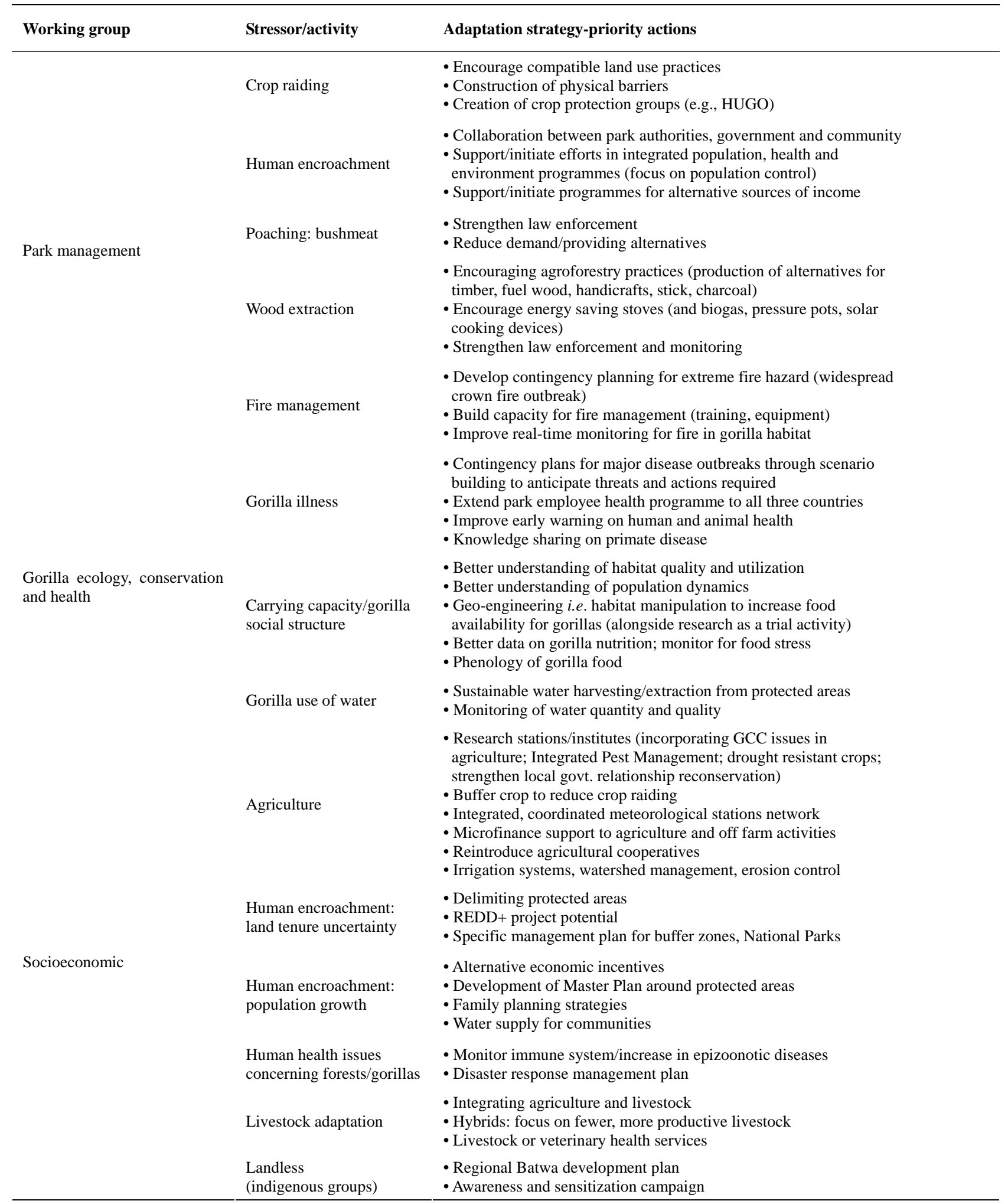

the adaptation planning framework, proved essential to collectively build experience and capacity. Furthermore, stakeholders were able to provide practical insight into the feasibility, cost effectiveness and immediate applicability of proposed adaptation actions. This engagement will prove vital in a region where resource allocation for 
conservation is constrained by funding shortages.

\subsection{Considering Data Limitations}

The performance of the vulnerability assessment and utility of the results is closely determined by the availability and quality of climate and species distribution data. Mountain gorilla distribution and ecology is relatively well understood, owing to decades of focused research by Primatologists. However, this data has never been subjected to climate change research.

The work by WCS scientists modeling projected climate changes across the Albertine Rift that informed this project suffered from a lack of detailed baseline climate data at the regional level. Downscaled climate data fails to account for local climate complexities that often drive ecological processes, particularly in mountain environments with complex topography [14].

In this project expert opinion proved essential in providing the additional insight that helped identify and in some cases compensate for uncertainties related to climate or SDM projections. This process also exposed numerous data gaps in need of further detailed research and monitoring. While many of the SDM outputs were considered erroneous, the exercise did prove useful in terms of identifying net primary productivity and specific gorilla food species ecology as a research area likely to reduce uncertainties in the subsequent modeling and improve the utility of outputs for adaptation planning in the future.

\subsection{Creating an Iterative Adaptation Framework}

One of the main lessons emerging from the project for conservation practitioners seeking to incorporate climate change considerations into their programmes is the need to create a robust adaptation planning framework that can allow the flexibility needed to periodically account for new information. This flexibility is needed both to account for improvements in understanding the uncertainties concerning the vulnerability assessment and new learning or best practice concerning adaptation actions. One recommendation emerging from the park management working group at the multi-stakeholder "climate camp" workshop was to immediately initiate a two year review cycle of park policy to allow for new climaterelated information and to incorporate feedback and learning from adaptation measures undertaken. This adaptive management, allowing for an iterative reflection on the overall availability and certainty of information, appears essential in the context of climate change vulnerability assessment and adaptation planning given the uncertainties.

The project also concluded that the first step should be to establish a team of decision makers that will coordinate priorities, consider proposed adaptation ideas and serve as an advisory directorate for climate change adaptation planning. The group would include key non-governmental organisations working on mountain gorilla conservation and human development in the landscape, as well as representatives for the Transboundary Core Secretariat. Other relevant multisectoral government agencies would be invited in due course in order to mainstream the adaptation activities across relevant sectors. Systems of flexibility will also need to be incorporated into this wider adaptation planning framework.

\section{CONCLUSIONS}

This article reviewed findings emerging from an assessment of climate change impacts upon the endangered mountain gorilla and its habitat. We emphasized stakeholder collaboration, data availability and the creation of an iterative adaptation framework as key lessons learnt from this process for the design of climate change vulnerability assessment and adaptation planning projects in tropical conservation management. These lessons are of direct relevance to conservation planners seeking to integrate climate change considerations into their conservation programmes.

While the SDM results were compromised by the data gaps related to historic species range, gorilla dietary plant species responses to climate change, and lack of fine resolution climate data, our modeling helped provide a focus for future research and monitoring that stands to significantly reduce the uncertainties of subsequent model outputs. However, this demonstrates the need for conservationists to view investment in climate change adaptation as a long-term commitment requiring the design of flexible planning systems capable of investing in baseline science and monitoring, and accommodating new findings and learning. Donor agencies should also be cognizant of this fact when designing funding cycles as few existing biodiversity funders provide opportunities to sustainably finance the entire vulnerability assessment, planning and implementation process.

Recognizing that data limitations and uncertainty are problems inherent within climate vulnerability assessments, expert opinion via structured multi-stakeholder collaboration throughout the project cycle helped to evaluate uncertainties, expose knowledge gaps, generate and prioritize adaptation actions and generally move beyond the model uncertainty impasse. However, these data issues do raise the question as to whether those seeking to initiate vulnerability assessments might first determine the minimum level of data quality required to produce meaningful assessment results within acceptable levels of uncertainty. 


\section{ACKNOWLEDGEMENTS}

The project detailed within this article was funded through the John T. and Catherine D. MacArthur grant number 92409 entitled "The implications of global climate change for mountain gorilla conservation in the Albertine Rift”. The authors gratefully acknowledge this financial support.

\section{REFERENCES}

[1] Dawson, T.P., Jackson, S.T., House, J.I., Prentice, I.C. and Mace, G.M. (2011) Beyond predictions: Biodiversity conservation in a changing climate. Science, 332, 53-58. doi:10.1126/science.1200303

[2] Zimmerer, K. (2000) The reworking of conservation geographies: Nonequilibrium landscapes and nature-society hybrids. Annals of the Association of American Geographers, 90, 356-369. doi:10.1111/0004-5608.00199

[3] Glick, P., Stein, B.E. and Edelson, N.A. (2011) Scanning the conservation horizon: A guide to climate change vulnerability assessment. National Wildlife Federation, Washington DC.

[4] Williams, S.E., Shoo, L.P, Isaac, J.L., Hoffman, A.A. and Langham, G. (2008) Towards an integrated framework for assessing the vulnerability of species to climate change. PLoS Biology, 6, 2621-2626. doi:10.1371/journal.pbio.0060325

[5] Heller, N.E. and Zavaleta, E.S. (2009) Biodiversity management in the face of climate change: A review of 22 years of recommendations. Biological Conservation, 142, 14-32. doi:10.1016/j.biocon.2008.10.006

[6] Rowland, E.L., Davison, J.E. and Graumlich, L.J. (2011) Approaches to evaluating climate change impacts on species: A guide to initiating the adaptation planning process. Environmental Management, 47, 322-327. doi:10.1007/s00267-010-9608-X

[7] Seimon, A., Watson, J., Dave, R., Oglethorpe, J. and Gray, E. (2011) A review of climate change adaptation initiatives within the African Biodiversity Collaborative Group NGO consortium, Wildlife Conservation Society, New York, and African Biodiversity Collaborative Group, Washington DC, $124 \mathrm{p}$.

[8] Young, B.E., Brooks, T., Butchart, S.H.M., Foden, W.B., Watson, J.E.M., Willis, S.G., et al. (2013) Climate change vulnerability assessment and adaptation planning for biodiversity: Emerging lessons from across the tropics. Conservation Letters, Unpublished.

[9] Belfiore, N., et al. (2010) The implications of global climate change for mountain gorilla conservation. White paper prepared by AWF, IGCP \& Ecoadapt, 129 p. http://ecoadapt.org/data/library-documents/The-Implicati ons-of-Global-Climate-Change-for-Mountain-Gorilla-Co nservation-in-Albertine-Rift.pdf

[10] Intergovernmental Panel on Climate Change (2007) Climate change 2007: The physical science basis. In: Solomon, S., Qin, D., Manning, M., Chen, Z., Marquis, K.B., Avery, M., et al., Eds., Contribution of Working Group 1 to the Fourth Assessment Report of the Intergovernmental Panel on Climate Change. Cambridge University Press,
Cambridge.

[11] Lawler, J.L., Tear, T.H., Pyke, C., Shaw, P., Gonzalez, P., Karieva, P., et al. (2009) Resource management in a changing and uncertain climate. Frontiers in Ecology and the Environment, 8, 35-43. doi:10.1890/070146

[12] Picton Phillipps, G. and Seimon, A. (2010) Potential climate change impacts in conservation landscapes of the Albertine Rift, World Conservation Society Albertine Rift Climate Assessment. White Paper Report No. 2. http://programs.wcs.org/Resources/Downloads/tabid/2801/ Default.aspx

[13] Hansen, L.T. and Hoffman, J.R. (2011) Climate savvy: Adapting conservation and resource management to a changing world. Island Press, Washington DC, 245 p.

[14] Seimon, A. and Picton Phillipps, G. (2010) Climatology of the mountain gorilla's domain, In: Belfiore, N., et al., The Implications of Global Climate Change for Mountain Gorilla Conservation. White paper prepared by AWF, IGCP \& Ecoadapt, 10-21.

http://ecoadapt.org/data/library-documents/The-Implicati ons-of-Global-Climate-Change-for-Mountain-Gorilla-Co nservation-in-Albertine-Rift.pdf

[15] IUCN (2002) IUCN red list of threatened species. IUCN, Gland, Switzerland. www.redlist.org

[16] Harcourt, A.H. (1995) Population viability estimates: Theory and practice for a wild gorilla population. Conservation Biology, 9, 134-142. doi:10.1046/j.1523-1739.1995.09010134.X

[17] Miller, P., Babaasa, D., Gerald-Steklis, N., Robbins, M.M., Ryder, O.A. and Steklis, D. (1998) Population biology and stimulation modeling working group report. In: Werikhe, S., Macfie, L., Rosen, N. and Miller, P., Eds., Can the Mountain Gorilla Survive? Population and Habitat Viability Assessment for Gorilla Gorilla Beringei. IUCN SSC Conservation Breeding Specialist Group, Apple Valley, 71-105.

[18] Durant, S. (2000) Dispersal patterns, social structure and population viability. In: Gosling, M. and Sutherland, B., Eds., Behaviour and Conservation. Cambridge University Press, Cambridge, 172-197.

[19] Garner, K.J. and Ryder, O.A. (1996) Mitochondrial DNA diversity in gorillas. Molecular and Phylogenetic and Evolution, 6, 39-48. doi:10.1006/mpev.1996.0056

[20] McNeilage, A. (2001) Diet and habitat use of two mountain gorilla groups in contrasting habitats in the Virungas. In: Robbins, M.M., Sicotte, P. and Stewart, K.J., Eds., Mountain Gorilla: Three Decades of Research at Karisoke. Cambridge University Press, Cambridge, 265-292. doi:10.1017/CBO9780511661631.011

[21] Watts, D.P. (1998) Long term habitat use by mountain gorillas (Gorilla gorilla beringei): Consistency, variation and home range size and stability. International Journal of Primatology, 19, 651-680. doi:10.1023/A:1020324909101

[22] Robbins, M.M. (2008) Feeding competition and female social relationships in mountain gorillas of Bwindi Impenetrable National Park, Uganda. International Journal of Primatology, 29, 999-1018. doi:10.1007/s10764-008-9275-4 
[23] Phillips, S.J. and Dudik, M. (2008) Modeling of species distributions with Maxent: New extensions and a comprehensive evaluation. Ecography, 31, 161-175. doi:10.1111/j.0906-7590.2008.5203.x

[24] Elith, J., Graham, C.H., Anderson, R.P., Dudik, M., Ferrier, S., Guisan, A., et al. (2006) Novel methods improve prediction of species' distributions from occurrence data. Ecography, 29, 129-151. doi:10.1111/j.2006.0906-7590.04596.x
[25] Thorne, J. and Wan Seo, C. (2010) Modeling species distribution under several climate change scenarios for mountain gorillas, In: Belfiore, N., et al. (2010) The implications of global climate change for mountain gorilla conservation, White paper prepared by AWF, IGCP \& Ecoadapt, 70.

http://ecoadapt.org/data/library-documents/The-Implicati ons-of-Global-Climate-Change-for-Mountain-Gorilla-Co nservation-in-Albertine-Rift.pdf 